\title{
Properdin deficiency
}

INSERM

\section{Source}

INSERM. (1999). Orphanet: an online rare disease and orphan drug data base. Properdin deficiency. ORPHA:2966

Properdin deficiency is a rare, hereditary, primary immunodeficiency due to a complement cascade protein anomaly characterized by sig nificantly increased susceptibility to Neisseria species infections. It only affects males, typically presenting with severe or fulminant meningococcal disease. 